\title{
PHYSICS WITH CHEMICALLY AND ISOTOPICALLY PURE SEMICONDUCTORS
}

\author{
E.E. HALLER \\ Lawrence Berkeley Laboratory and University of California, Berkeley, CA 94720, USA
}

\begin{abstract}
Chemically and isotopically pure semiconductors offer a wealth of interesting physics. We review a number of impurity complexes which were discovered in ultra-pure germanium. They have led the way to the widely pursued studies of hydrogen in numerous semiconductors. Isotope related effects and processes include neutron transmutation doping, a technique used for a number of silicon and germanium devices. Isotopically pure and deliberately mixed crystals of germanium have been grown recently and have been used to study the dependence of the indirect bandgap and phonon properties on the mass and mass disorder of the nuclei. The large number of stable isotopes of the various semiconductors present a great potential for basic and applied studies. Semiconductor isotope engineering may become a reality because of the new economic and political world order.
\end{abstract}

PACS numbers: 71.55.-i, 63.20.-e, 66.30.- $\mathrm{h}, 28.60 .+\mathrm{s}$

\section{Introduction}

Purification of semiconductors has remained a primary challenge from the early days of experimentation to today's sophisticated research and application of semiconductors in a wide variety of devices. If one wants to understand or make use of the immense diversity of properties of the many known semiconductors through the introduction of dopant impurities and/or native defects, one preferably starts with materials which are sufficiently pure for the given task.

Perhaps the biggest challenge for the purification of semiconductors has come from the application of silicon and germanium in large volume $p$ - $i$ - $n$ junctions used for the detection and measurement of ionizing radiation [1]. In order to obtain fully depleted detectors with volumes of tens to hundreds of $\mathrm{cm}^{3}$ at bias voltages of up to a few thousand volts, one has to synthesize crystals with net-dopant concentrations in the $10^{10}$ to $10^{11} \mathrm{~cm}^{-3}$ range.

Since only. the difference between the acceptor and the donor concentrations needs to be small in this particular application, one might be led to believe that this is less of a challenge than reading absolute impurity concentrations of this order of magnitude. Indeed, there exists a process which allows very precise compensation of acceptors by mobile, interstitial lithium donors. This so-called "lithium drift". 
process has been used for over ten years in the production of large volume $\mathrm{Si}$ and $\mathrm{Ge}$ radiation detectors $[2,3]$. Because of severe room temperature instability problems with $\mathrm{Ge}(\mathrm{Li})$ detectors, a large and ultimately successful effort was launched in the 1970 s to develop ultra-pure Ge with purities in the low $10^{10} \mathrm{~cm}^{-3}[4,5]$.

It is instructive to realize that at such purity levels we deal with one electrically active impurity for every $10^{12}$ semiconductor atoms! If net-impurity concentrations of this order of magnitude must be achieved throughout large crystal volumes, it is mandatory that the individual, absolute impurity concentrations are of the same magnitude. It is simply not possible to grow large crystals with close to perfect compensation extending over large volumes.

Semiconductor physics has been of significant help on the difficult and long path to such extremely pure materials but at the same time it has also profited through the discovery of a large number of impurity and defect complexes which have unique and interesting properties [6]. Much of what we have learned from the development and the study of ultra-pure crystals has or may become useful in some form for doped crystals.

A good example for this kind of knowledge transfer has been the study of hydrogen in semiconductors. The first electronic effects of hydrogen in semiconductors were discovered during the development of ultra-pure germanium [7-9]. Both passivation of multilevel acceptors $[10,11]$ and activation of neutral impurities manifest themselves in ultra-pure germanium. In the early 1980s this knowledge was transferred to silicon and led to the discovery of the eflective passivation of acceptors and donors [12]. Today the study of hydrogen in practically all elemental and compound semiconductors is pursued worldwide $[13,14]$.

We can expand the concept of purity to include both chemical and isotopic purity. The latter starts to attract attention because sizable quantities of isotopically pure semiconductor materials have become available through the opening of markets in the former Soviet Union. The international high energy physics collaboration for the determination of the neutrino mass through the study of double beta decay in the isotope ${ }^{76} \mathrm{Ge}$ required several tens of kilograms of this highly enriched isotope in the form of ultra-pure single crystals [15]. These crystals were made into large volume coaxial $p-i-n$ diodes which can detect any internal decays with very high efficiency.

Smaller quantities of isotopically pure and deliberately mixed Ge crystals have been grown [16] and used for a variety of studies. These studies address the dependence of the bandgap on isotope mass $[17,18]$, the properties of phonons in isotopically pure and deliberately mixed crystals [19-21], the local vibrational modes of impurities in isotopically engineered crystals [22], the conduction of heat [23], and the properties of the chalcogenide double donor Se in Ge.

An interesting experiment on the diffusion of $\mathrm{Ga}$ in $\mathrm{GaAs}$ was recently conducted using the stable isotopes ${ }^{69} \mathrm{Ga}$ and ${ }^{71} \mathrm{Ga}$ [24]. Plans exist to grow isotope superlattices of isotopically enriched and ultra-pure Ge [25]. Such superlattices can be doped after they have been grown by the Neutron transmutation doping (NTD) process. The separation of the crystal growth process from doping will allow the formation of interesting superlattices which can be doped sequentially several times to ever higher levels [26]. 
In this paper we will first review briefly the major findings from the studies of ultra-pure Ge, continue with a discussion of some applications of "purely doped" crystals and finally present recent and future experiments with isotopically pure semiconductors.

\section{Impurity complexes in ultra-pure germanium}

The purification and growth of large volume Ge single crystals with residual impurity concentrations in the $10^{10} \mathrm{~cm}^{-3}$ range posed some interesting challenges in regard to the choice of materials (crucibles, ambient gasses, crystal puller envelope, etc.) which would be suitable for such an endeavor, as well as to the choice of characterization techniques which would offer sufficient sensitivity and selectivity. The successful purification and crystal growth techniques have been reviewed in detail $[5,6]$ and we will concentrate here on the unusual aspects of the residual impurities. We recall that practically all high quality ultra-pure Ge is grown in a pure hydrogen atmosphere of ambient pressure from a melt contained in a pure silica crucible. The crystals contain hydrogen and oxygen at concentrations of $\approx 10^{14} \mathrm{~cm}^{-3}$. Both impurities reside electrically inactive in the crystal. Hall [27] discovered that upon heating ultra-pure Ge to temperatures around $400^{\circ} \mathrm{C}$ followed by rapid quenching, a shallow acceptor at a concentration of $\approx 10^{11} \mathrm{~cm}^{-3}$ was formed. The acceptor is not stable at room temperature and transforms into a shallow donor. The donor can be annealed away at temperatures slightly above $100^{\circ} \mathrm{C}$. Using photothermal ionization spectroscopy discovered by Lifshitz and Nad [28], we analyzed these rapid quenching acceptors and donors and found that both had rather unusual properties. Substitution of hydrogen with deuterium induced a measurable shift in the ground state energies of the acceptor and the donor [29]. This was the first direct proof of the presence of hydrogen in these novel centers.

The acceptor was the first one in a semiconductor with a degenerate valence band top which exhibited a split $1 s$ ground state manifold. The ground-state splitting and the isotope shift were found to be caused by the reduced symmetry and an axial strain field of the hydrogen-silicon impurity complex [30]. The hydrogen "activates" a neutral silicon atom to become a shallow acceptor A(II,Si). In crystals grown from graphite crucibles we found an analogous carbon-hydrogen acceptor $\mathrm{A}(\mathrm{HI}, \mathrm{C})$. Theoretical calculations are in agreement with these assignments [31]. Because the $1 s$ ground-state components of $\mathrm{A}(\mathrm{H}, \mathrm{Si})$ and $\mathrm{A}(\mathrm{H}, \mathrm{C})$ are, unlike normal acceptors, insensitive to mechanical stress, one can expect a very sharp ground state to bound excited state transitions. Indeed, the sharpest $1 s$ ground state to bound excited state electronic transitions have been recorded with $A(D, C)$ (D stands for deuterium) acceptors in ultra-pure Ge (Fig. 1).

In the meantime, a wealth of spectroscopy studies using external perturbations such as stress and magnetic fields have been performed on these centers $[6,30,32-35]$. Further discoveries were made with multivalent acceptors and hydrogen in germanium and silicon. The double acceptors $\mathrm{Be}$ and $\mathrm{Zn}$ form shallow acceptors in $\mathrm{Ge}$ upon binding one hydrogen atom [10, 36]. In Si the Be-H acceptor has been shown to be a tunneling hydrogen center [37-39]. Theoretical calculations support a structure with the hydrogen atom in local energy minima along 


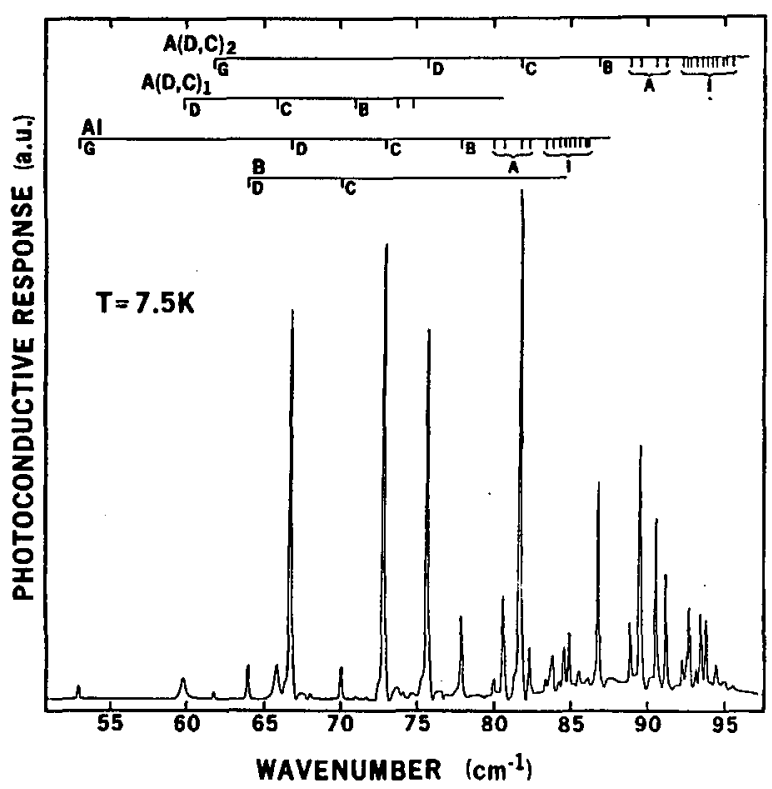

Fig. 1. The photothermal ionization spectrum of the shallow carbon-deuterium complex $A(D, C)$ in ultra-pure Ge. The ground state of $A(D, C)$ is split by $1 . n 8$ meV leading to two sets of hydrogenic line series. At $T=7.5 \mathrm{~K}$ the upper ground state component is only lightly populated, resulting in relatively weak line intensities $\left(A(D, C)_{1}\right)$. The hydrogenic line series of the residual acceptors $A l$ and $B$ are fully resolved. The sample size was $\approx(0.5)^{3}$ and the total acceptor concentration was $\approx 10^{11} \mathrm{~cm}^{-3}$.

the six equivalent [100] directions [31]. The original tunneling model which was based on hydrogen residing in four equivalent sites along the [111] directions was successfully modified for the Be-H center in Si [40].

The center with the richest spectrum of hydrogen related effects is the substitutional triple acceptor $\mathrm{Cu}$ in $\mathrm{Ge}$. Isotope shifts in the acceptor ground state using crystals doped with $\mathrm{H}$, with $\mathrm{D}$ and with both $\mathrm{II}$ and $\mathrm{D}$ established the presence of two hydrogen atoms in this $\mathrm{A}\left(\mathrm{Cu}, \mathrm{H}_{2}\right)$ center [11] (Fig. 2). The spectroscopic studies were expanded to include tritium. The key finding was that with two hydrogen atoms bound to copper a complicated ground-state manifold resulted from the nuclear motion of the protons. Substitution of one or both hydrogen atoms with deuterium or tritium led to a freezing of the nuclear motion accompanied by the reduction of the electronic ground-state multiplet to a single level. The Devonshire model of the hindered rotor proved to give a quantitative description of the properties of the $\mathrm{A}\left(\mathrm{Cu}, \mathrm{H}_{2}\right)$ centers [41].

Summarizing this section on ultra-pure Ge we can state that only the great purity made possible the discovery and the successful identification of a number of hydrogen containing centers. Both activation of neutral impurities and partial and full passivation of multivalent acceptors was established. These studies led di- 


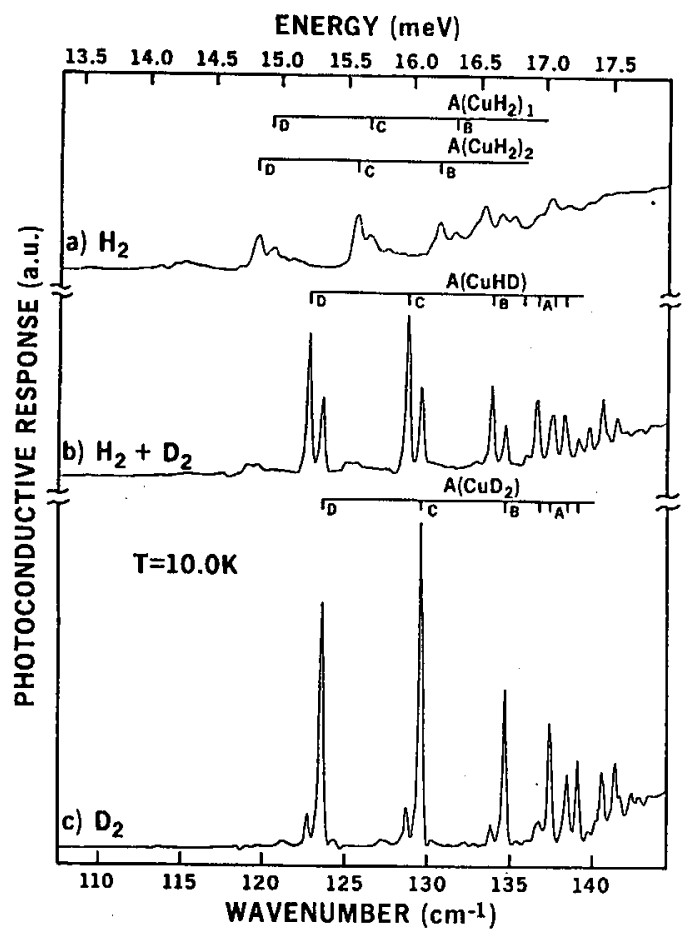

Fig. 2. Spectra of the copper-dihydrogen, copper-hydrogen-deuterium and copperdideuterium complexes in ultra-pure Ge. Spectrum (a) of a crystal grown in $\mathrm{H}_{2}$ shows a broad line due to the tunneling motion of hydrogen in the $\mathrm{Cu}-\mathrm{H}_{2}$ complexes; spectrum (c) was recorded with a crystal grown in $\mathrm{D}_{2}$. It shows only one sharp series of lines because the higher mass of $D$ suppresses tunneling; spectrum (b) of a crystal grown in $\mathrm{H}_{2}+\mathrm{D}_{2}$ shows an additional, third series of lines due to $\mathrm{C}-\mathrm{H}, \mathrm{D}$ acceptor complexes.

rectly to the hydrogen passivation studies which are still conducted with numerous semiconductors today [13].

\section{Isotope effects in semiconductors}

With very few exceptions most semiconductor research and technology is completely oblivious to the existence of stable semiconductor isotopes. This is quite understandable for several reasons. First, it has been very costly to obtain even the smallest quantities of isotopically enriched semiconductor materials. Second, most effects caused by differences in isotope nuclear masses are small and therefore only of interest for specific basic studies.

\subsection{Neutron transmutation doping (NTD)}

Transmutation of stable semiconductor isotopes into different elements acting as dopants following thermal neutron capture has made use of specific isotopes 
for some time. The technologically most important case is doping of ultra-pure $\mathrm{Si}$ with thermal neutrons. The resulting homogeneity of the phosphorus donor concentration is used in the fabrication of the majority of high voltage, high power silicon controlled rectifiers (SCRs) $[42,43]$. The neution transmutation doping process in silicon is based on the following reaction:

$$
{ }_{14}^{30} \mathrm{Si}+n \rightarrow{ }_{14}^{31} \mathrm{Si} \frac{\beta^{-}}{T_{1 / 2}=2.6 \mathrm{hrs}} \rightarrow{ }_{15}^{31} \mathrm{P}+e^{-}+\bar{\nu}_{e} .
$$

The other isotopes are ${ }^{28} \mathrm{Si}(92.23 \%)$ and ${ }^{29} \mathrm{Si}(4.61 \%)$. Only $3.10 \%$ of natural silicon is ${ }_{14}^{30} \mathrm{Si}$. The maximum phosphorus concentration is practically limited to levels around $10^{16} \mathrm{~cm}^{-3}$. This limit is, of course, not a theoretical limit given by the total concentration of ${ }_{14}^{30} \mathrm{Si}$. It is related to the maximum available flux of thermal neutrons, the radiation damage caused by fast neutrons and to secondary transmutation of $\mathrm{P}$ into $\mathrm{S}$, a deep double donor.

Other semiconductors have been successfully doped by NTD. Germanium, which has five stable isotopes, becomes $p$-type. The majority impurities are gallium acceptors created in the decay of ${ }_{32}^{71} \mathrm{Ge}$. The compensating donors are arsenic created in the decay of ${ }_{32}^{75} \mathrm{Ge}$. The NTD process has been most successful in the development of very low temperature Ge thermistors which are used in the bolometric detection of very far infrared electromagnetic radiation (1 mm> $\lambda>250 \mu \mathrm{m}$ ). The widest application of such low temperature sensors is occurring in the field of submillimeter radioastronomy and astrophysics. All the advanced large radio telescopes are currently equipped with bolometer arrays using NTD Ge operated at temperatures between 100 and $300 \mathrm{mK}$ [14].

TABLE I

NTD Ge thermistor data.

\begin{tabular}{c|c|c|c|c|c}
\hline \hline NTD\# & $\begin{array}{c}n \text { Dose } \\
{\left[10^{18} \mathrm{~cm}^{-2}\right]}\end{array}$ & $\begin{array}{c}N_{\mathrm{Ga}} \\
{\left[10^{16} \mathrm{~cm}^{-3}\right]}\end{array}$ & $\begin{array}{c}N_{\mathrm{As}} \\
{\left[10^{16} \mathrm{~cm}^{-3}\right]}\end{array}$ & $\begin{array}{c}N_{\mathrm{Se}} \\
{\left[10^{15} \mathrm{~cm}^{-3}\right]}\end{array}$ & $\begin{array}{c}N_{\mathrm{Ga}}-\sum N_{\mathrm{D}} \\
{\left[10^{16} \mathrm{~cm}^{-3}\right]}\end{array}$ \\
\hline 4 & 0.338 & 0.994 & 0.283 & 0.186 & 0.674 \\
5 & 0.750 & 2.21 & 0.629 & 0.413 & 1.50 \\
13 & 1.24 & 3.65 & 1.04 & 0.683 & 2.47 \\
15 & 1.54 & 4.53 & 1.29 & 0.849 & 3.07 \\
16 & 2.07 & 6.09 & 1.73 & 1.14 & 4.13 \\
18 & 2.61 & 7.67 & 2.19 & 1.44 & 5.20 \\
26 & 2.82 & 8.29 & 2.36 & 1.55 & 5.62 \\
28 & 3.07 & 9.03 & 2.57 & 1.69 & 6.11 \\
12 & 3.33 & 9.79 & 2.79 & 1.83 & 6.64 \\
25 & 4.20 & 12.3 & 3.52 & 2.31 & 8.37
\end{tabular}


Figure 3 shows the logarithm of the resistivity of ten selected NTD Ge crystals as a function of $T^{-1 / 2}$. Iole conduction occurs via variable range hopping as predicted by Shklovskii's and Efros' theory [45]. Neutron exposure and the resulting acceptor and donor concentrations are given in Table I. What makes NTD attractive is the extremely good dopant uniformity. The vcry large size of a nuclear reactor compared to the size of a semiconductor crystal guarantees a very homogeneous neutron flux. The absorption crnss sections for the usual semiconductor nuclei are relatively small $\left(\approx 10^{24} \mathrm{~cm}^{-2}\right)$ resulting in minimal self shadowing and, in the case of $\mathrm{Ge}$, the various stable isotopes have been mixed thoroughly since their birth in nucleosynthesis. In order to fully profit from these advantages of NTD one must use ultra-pure semiconductors. Much of the floating zone Si is grown for applications using NTD.

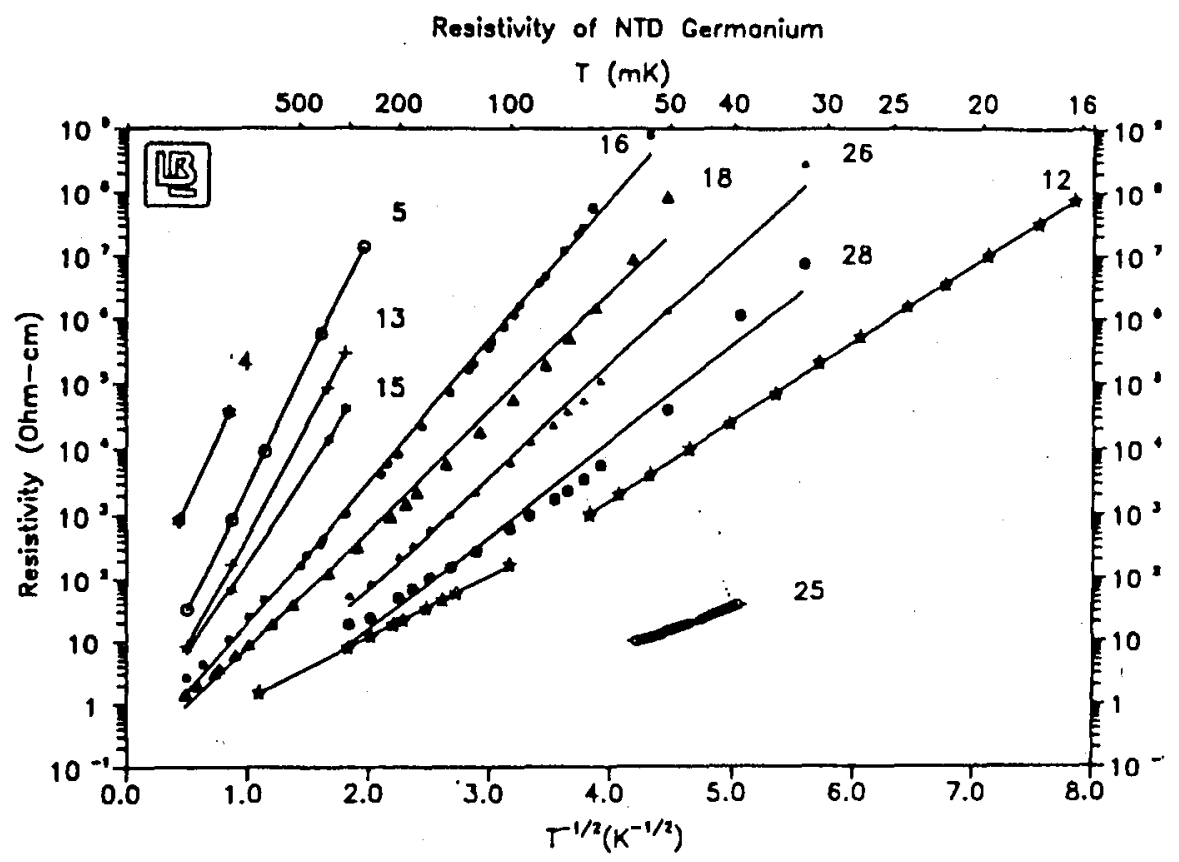

Fig. 3. Logarithm of the resistivity $\rho$ as a function of $T^{-1 / 2}$ for ten selected NTD Ge crystals. The neutron dose and the resulting dopant concentrations are listed in Table I. (Courtesy of J. Beeman, Lawrence Berkeley Laboratory).

\subsection{Isotope superlattices}

The availability of each of the stable Ge isotopes in highly enriched form has led to a proposal to grow isotope superlattices [25]. MBE grown undoped ${ }^{x} \mathrm{Ge}:{ }^{y} \mathrm{Ge}$ superlattices hold promise for interesting phonon studies. For superlattices with very small numbers of atomic layers of each isotope, one expects a wealth of Brillouin zone folding phenomena [46]. The growth of thicker ${ }^{70} \mathrm{Ge}:{ }^{74} \mathrm{Ge}$ superlattices 
followed by NTD allows the formation of very abrupt $n-i-p-i$ superlattices. The interface abruptness in the different isotope layers is expected to be sharper than when growth with dopants is performed. Studies of this kind will allow a quantitative determination of dopant and host atom interdiffusion at the atomic level.

A recent study of this kind in GaAs made use of superlattices consisting of ${ }_{31}^{69} \mathrm{GaAs}$ and ${ }_{31}^{71} \mathrm{GaAs}$ layers [24]. Arsenic is monoisotopic and does not play a role in this study. Secondary ion mass spectroscopy (SIMS) was used to measure $\mathrm{Ga}$ interdiffusion between the individual layers after annealing at $900^{\circ} \mathrm{C}$ for $10 \mathrm{hrs}$ (Fig. 4). It is unfortunate that the substrates for these experiments were strongly $\mathrm{Si}$ doped and that the $\mathrm{Si}$ appears to have caused deviations of the $\mathrm{Ga}$ diffusion constant from the equilibrium value in GaAs.
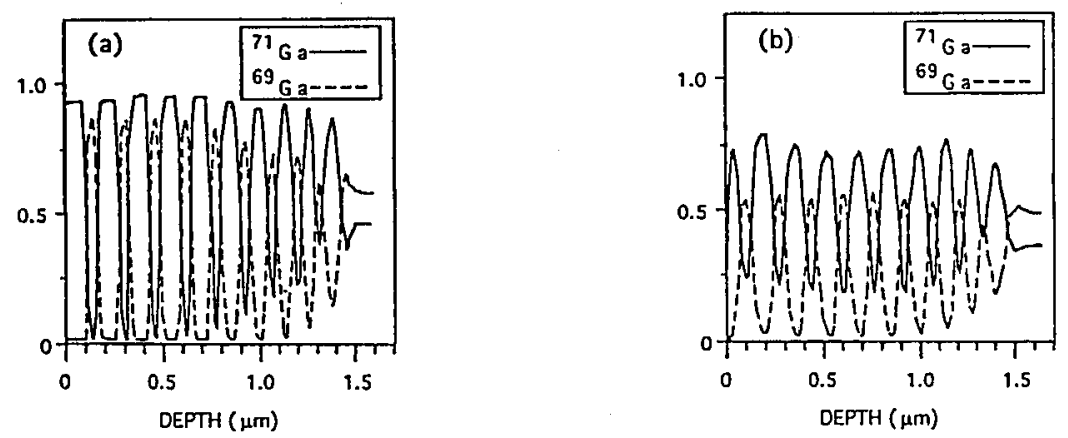

Fig. 4. Normalized ${ }_{31}^{69} \mathrm{Ga}$ and ${ }_{31}^{71} \mathrm{Ga}$ profiles measured by SIMS. (a) An as-grown sample, and (b) a sample annealed at $900^{\circ} \mathrm{C}$ for $10 \mathrm{hrs}$. Vertical axes denote relative fractions. (Courtesy Tan et al., Ref. [24]).

\subsection{Bulk properties depending on isotopic composition}

The bandgap of a semiconductor depends very lightly on the isotopic composition of its constituents. Recent photoluminescence experiments by Davies et al. $[17,18]$ used isotopically and chemically pure Ge crystals to determine this dependence. The introduction of small concentrations of acceptors and donors proved useful in obtaining very accurate data through no-phonon (NP) transitions of impurity bound excitons (Fig. 5). The indirect bandgap $E_{1}$ is found to move to higher energy with increasing atomic Ge mass $A$ (Fig. 6):

$$
\mathrm{d} E_{\mathrm{I}} / \mathrm{d} A=0.35 \pm 0.02 \mathrm{meV} .
$$

The isotope dependence of the bandgap has two contributions: electron-phonon coupling and the isotope dependence of the lattice constant. From accurate experimental data one can estimate both of these contributions. The lattice constant effect, or volume term, gives $\left(d \mathrm{E}_{\mathrm{I}} / \mathrm{d} A\right)_{v}=0.044 \mathrm{meV}$. The electron-phonon term is estimated using the known temperature dependence of the bandgap and a simple harmonic oscillator model for the mean-square displacement $\left\langle u^{2}\right\rangle$ of the atoms. 


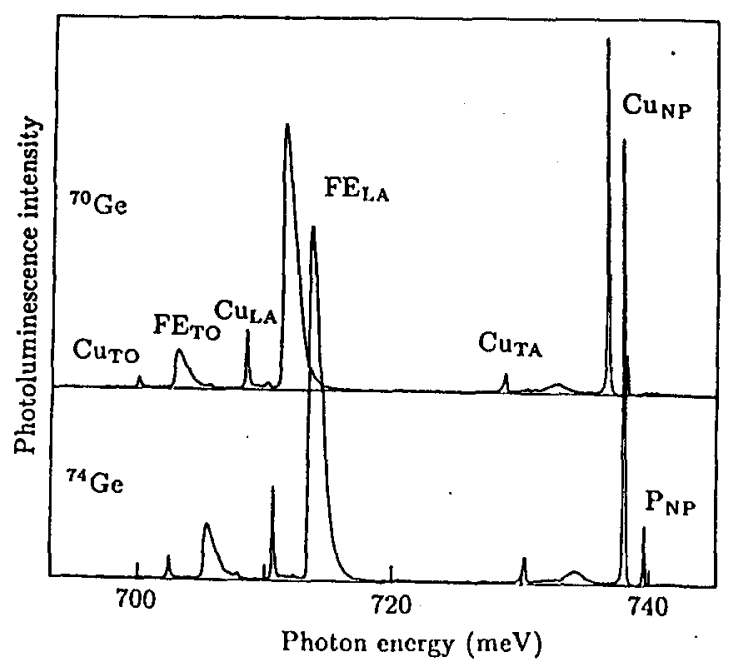

Fig. 5. Luminescence from the decay of free excitons (FE) and excitons bound to $\mathrm{Cu}$ triple acceptors and $P$ donors in ${ }^{70} \mathrm{Ge}$ and ${ }^{74} \mathrm{Ge}$ at $4.2 \mathrm{~K}$. The subscripts indicate the $L$-point phonons involved in each transition (Courtesy of Gordon Davies et al., Ref. [18]).

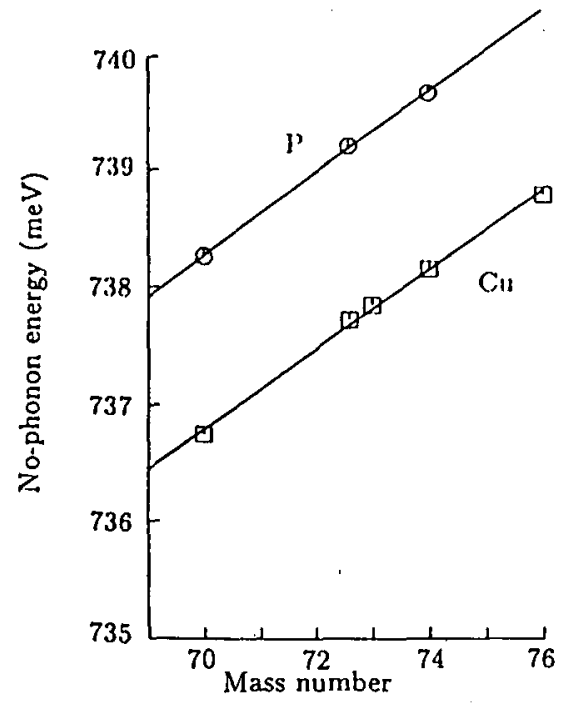

Fig. 6. Exciton no-phonon recombination energies in several isotopically pure and one natural Ge crystal. The $\mathrm{P}$ donor and $\mathrm{Cu}$ acceptor bound excitons show the same isotope mass dependence, i.e., the dependence of the band gap on isotope mass. (Courtesy of G. Davies et al., Ref. [18]). 
TABLE II

Isotopes of elements*.

\begin{tabular}{|c|c|c|c|}
\hline Isotope & Abundance (\%) & $\begin{array}{l}\text { Thermal neutron capture } \\
\text { Cross section }\left(\times 10^{-24} \mathrm{~cm}^{2}\right)\end{array}$ & $\begin{array}{l}\text { Neutron transmutation } \\
\therefore \quad \text { product }\end{array}$ \\
\hline${ }_{5}^{10} \mathrm{~B}$ & 19.8 & $\left\{\begin{array}{l}3838(n, \alpha) \\
0.52\end{array}\right.$ & $\begin{array}{l}{ }_{3}^{7} \mathrm{Li}+{ }_{2}^{4} \mathrm{IIe} \\
{ }_{5}^{11} \mathrm{~B}\end{array}$ \\
\hline${ }_{5}^{11} \mathrm{~B}$ & 80.2 & 0.005 & ${ }_{6}^{12} \mathrm{C}$ \\
\hline${ }_{6}^{12} \mathrm{~B}$ & 98.89 & 0.0034 & ${ }_{6}^{13} \mathrm{C}$ \\
\hline${ }_{6}^{13} \mathrm{C}$ & 1.11 & $9 \times 10^{-4}$ & ${ }_{7}^{14} \mathrm{~N}$ \\
\hline${ }_{7}^{14} \mathrm{~N}$ & 99.63 & 0.076 & ${ }_{7}^{15} \mathrm{~N}$ \\
\hline${ }_{7}^{15} \mathrm{~N}$ & 0.37 & $4 \times 10^{-5}$ & ${ }_{8}^{16} \mathrm{O}$ \\
\hline${ }_{8}^{16} \mathrm{O}$ & 99.76 & $1.78 \times 10^{-4}$ & ${ }_{8}^{17} \mathrm{O}$ \\
\hline${ }_{8}^{17} \mathrm{O}$ & 0.038 & $0.235(\mathbf{n}, \alpha)$ & ${ }_{6}^{14} \mathrm{C}+{ }_{2}^{4} \mathrm{IIe} \rightarrow{ }_{7}^{14} \mathrm{~N}$ \\
\hline${ }_{8}^{18} \mathrm{O}$ & 0.204 & $1.58 \times 10^{-4}$ & ${ }_{9}^{19} \mathrm{~F}$ \\
\hline${ }_{13}^{27} \mathrm{Al}$ & 100 & 0.231 & ${ }_{14}^{28} \mathrm{Si}$ \\
\hline${ }_{14}^{28} \mathrm{Si}$ & 92.23 & 0.17 & ${ }_{14}^{29} \mathrm{Si}$ \\
\hline${ }_{14}^{29} \mathrm{Si}$ & 4.67 & 0.10 & ${ }_{14}^{30} \mathrm{Si}$ \\
\hline${ }_{14}^{30} \mathrm{Si}$ & 3.10 & 0.11 & ${ }_{15}^{31} \mathrm{P}$ \\
\hline${ }_{15}^{31} \mathrm{P}$ & 100 & 0.18 & ${ }_{16}^{32} \mathrm{~S}$ \\
\hline${ }_{16}^{32} \mathrm{~S}$ & 95.02 & 0.53 & ${ }_{16}^{33} \mathrm{~S}$ \\
\hline${ }_{16}^{33} \mathrm{~S}$ & 0.75 & $0.095(\mathrm{n}, \alpha)$ & ${ }_{14}^{30} \mathrm{Si}+{ }_{2}^{4} \mathrm{He}$ \\
\hline${ }_{16}^{34} \mathrm{~S}$ & 4.21 & 0.24 & ${ }_{17}^{35} \mathrm{Cl}$ \\
\hline${ }_{16}^{36} \mathrm{~S}$ & 0.017 & 0.15 & ${ }_{17}^{37} \mathrm{Cl}$ \\
\hline${ }_{30}^{64} \mathrm{Zn}$ & 48.6 & 0.78 & ${ }_{29}^{65} \mathrm{Cu}$ \\
\hline${ }_{30}^{66} \mathrm{Zn}$ & 29.7 & 1.0 & ${ }_{30}^{67} \mathrm{Zn}$ \\
\hline${ }_{30}^{67} \mathrm{Zn}$ & 4.1 & 7.0 & ${ }_{30}^{68} \mathrm{Zn}$ \\
\hline${ }_{30}^{68} \mathrm{Zn}$ & 18.8 & 0.88 & ${ }_{31}^{69} \mathrm{Ga}$ \\
\hline${ }_{30}^{70} \mathrm{Zn}$ & 0.62 & 0.098 & ${ }_{31}^{71} \mathrm{Ga}$ \\
\hline${ }_{31}^{69} \mathrm{Ga}$ & 60.1 & 1.7 & ${ }_{30}^{70} \mathrm{Zn}(0.2 \%)$ \\
\hline & & & ${ }_{32}^{70} \mathrm{Ge}(99.8 \%)$ \\
\hline${ }_{31}^{71} \mathrm{Ga}$ & 39.9 & 4.7 & ${ }_{32}^{72} \mathrm{Ge}$ \\
\hline${ }_{32}^{70} \mathrm{Ge}$ & 20.5 & 3.25 & ${ }_{31}^{71} \mathrm{Ga}$ \\
\hline${ }_{32}^{72} \mathrm{Ge}$ & 27.4 & 1.0 & ${ }_{32}^{73} \mathrm{Ge}$ \\
\hline${ }_{32}^{73} \mathrm{Ge}$ & 7.8 & 15.0 & ${ }_{32}^{74} \mathrm{Ge}$ \\
\hline${ }_{32}^{74} \mathrm{Ge}$ & 36.5 & 0.36 & ${ }_{33}^{75} \mathrm{As}$ \\
\hline${ }_{32}^{76} \mathrm{Ge}$ & 7.8 & 0.16 & ${ }_{34}^{76} \mathrm{Se}$ \\
\hline
\end{tabular}

*All data from Ref. [50]. 
At low temperatures the power expansion of the mean-square displacement leads to $\left\langle u^{2}\right\rangle \propto 1 / \sqrt{A}$, with $A=$ isotope mass. A simple estimate leads to

$$
\left(\mathrm{d} E_{\mathrm{I}} / \mathrm{d} A\right)_{\mathrm{e}-\mathrm{ph}}=0.22 \text { to } 0.30 \mathrm{meV} \text {. }
$$

The two contributions add to a value range which is close to the experimentally determined mass dependence. A recent first-principle calculation [47], on the other hand, leads to a slight overestimate $\left(d E_{\mathrm{I}} / \mathrm{d} A\right)_{\mathrm{e}-\mathrm{ph}}=0.42 \mathrm{meV}$. It will be interesting to explore the isotope mass dependence of other conduction band extrema.

The phonon energies $h \omega$ depend most directly on the isotope mass $h \omega \propto$ $1 / \sqrt{A}$. Experimentally this dependence is fully verified.

An interesting question arises when one explores the effects of isotope disorder on the four different types of phonons. Line broadening and shifts in $h \omega$ may be expected. Two groups have reported experimental studies of these effects $[20,21] . \wedge$ s expected, the disorder effects were largest in isotope engineered $\mathrm{Ge}$ crystals containing equal parts of ${ }^{70} \mathrm{Ge}$ and ${ }^{76} \mathrm{Ge}$ [48].

\section{Summary and outlook}

We have shown that chemically and isotopically pure semiconductors offer a wealth of interesting physics. The chemical purification has been pushed as far as necessary for most applications and one cannot expect that fundamental semiconductor studies could generate an incentive large enough to strive for even higher purities. One new application of a high purity semiconductor involves the development of ultra-pure liquid phase epitaxy grown GaAs. Epilayers of up to $100 \mu \mathrm{m}$ with net-donor concentrations $N_{\mathrm{D}}-N_{\mathrm{A}} \simeq 5 \times 10^{12} \mathrm{~cm}^{-3}$ and moderate compensation (0.3-0.7) have been grown successfully.[49]. GaAs epilayers which have net-impurity concentrations of this order of magnitude may become useful for room temperature X-ray detector applications and low temperature far infrared photoconductor devices. Such pure crystals are expected to exhibit hydrogenic donor spectra with unprecedented resolution. Extreme purity is of great importance for high resolution spectroscopy studies because the Bohr orbits of the ground- and the bound-excited donor states are extremely large $(\geq 100 \AA)$, leading to wave function overlap and line broadening already at very low impurity concentrations.

Using isotopically controlled superlattices one will be able to make very accurate interdiffusion measurements. NTD may be especially useful with isotopically engineered III-V and II-VI compound and alloy semiconductor systems.

In closing, we would like to draw the attention to Table II which lists but a few of the stable isotopes of elements which are of current interest for semiconductor science and technology. Many more interesting elements which are either a component of a semiconductor or can act as dopants can be found in Ref. [50]. Semiconductor isotope enginecring is evolving.

\section{Acknowledgments}

Many of the results obtained with ultra-pure Ge have strongly depended on the work of W.L. Hansen and the continuous encouragement of F.S. Goulding. We 
are greatly indebted to V. Ozhogin of the Kurchatov Institute in Moscow for collaborating with us on the purification, growth and study of isotopically engineered Ge single crystals. K. Itoh has grown most of these single crystals. We have profited greatly from our close interactions with G. Davies and E. Lightowlers at Kings College, London, and with M. Cardona and his group at the Max-Planck-Institute, Stuttgart. The isotope related work was supported in part by the Laboratory Directed Research and Development Program of the Lawrence Berkeley Laboratory and in part by NASA contract W17605 under interagency agreement with the US Department of Energy Contract DE-AC03-76SF00098. The ultra-pure Ge work was supported by the Office of Energy Research, Office of Health and Environmental Research, U.S. Department of Energy under Contract No. DE-AC03-76SF00098.

\section{References}

[1] E.E. IIaller, F.S. Goulding, in: IIandbook on Semiconductors, Ed. C. IIilsum, Vol. 4, Ch. 6C, North-IIolland, 1981, p. 799; E.E. IIaller, F.S. Goulding, in: Handbook on Semiconductors, Ed. C. IIilsum, Vol. 4, $2^{\text {nd }}$ ed., Elsevier North-IIolland Inc., New York 1991.

[2] J.T. Walton, E.E. IIaller, in: Proc. Mater. Res. Soc. 1982 Annual Meeting, Symposium $F$, Eds. E.E. Haller, H.W. Kraner, W.A. Higinbotham, Elsevier Science Publishing Co. Inc., New York, Mater. Res. Soc. Proc. 16, 141 (1983).

[3] J.T. Walton, N. Derhacobian, Y.K. Wong, E.E. IIaller, Appl. Phys. Lett., in press.

[4] E.E. Haller, W.L. IIansen, G.S. Ilubbard, F.S. Goulding, IEEE Trans. Nucl. Sci. NS-23, No. 1, 81 (1976).

[5] W.L. Hansen, E.E. ITaller, in: Proc. Mater. Res. Soc. 1982 Annual Meeting, Symposium $F$, Eds. E.E. Haller, H.W. Kraner, W.A. Higinbotham, Elsevier Science Publishing Co. Inc., New York, Mater. Res. Soc. Proc. 16, 1 (1983).

[6] E.E. Haller, W.L. IIansen, F.S. Goulding, Adv. Phys. 30, No. 1, 93 (1981).

[7] E.E. Haller, Phys. Rev. Lelt. 40, No. 9, 584 (1978).

[8] E.E. Haller, Defects and Radiation Effects in Semiconductors 1978, Ed. J.H. Albany, Inst. Phys. Conf. Ser. 46, 205 (1979).

[9] W.L. Hansen, E.E. Iraller, P.N. Luke, IEEE Trans. Nucl. Sci. NS-29, No. 1, 738 (1982).

[10] R.E. McMurray, Jr., N.M. Haegel, J.M. Kahn, E.E. Haller, Solid State Commun. 61, No. 1, 27. (1987).

[11] J.M. Kahn, E.E. IIaller, L.M. Falicov, in: Proc. 18th Internat. Conf. on the Physics of Semiconductors, Ed. O. Engström, World Scientific, Singapore 1987, p. 1003.

[12] J.I. Pankove, R.O. Wance, J.E. Berkeyheiser, Appl. Phys. Lett. 45, 1100 (1984).

[13] See articles in Hydrogen in Semiconductors, Eds. J. Pankove, N. Johnson, in series Semiconductors and Semimetals, Vol. 34, Academic Press, Orlando 1991.

[14] E.E. Haller, in: Proc. 20th Internat. Conf. on the Physics of Semiconductors, Eds. E.M. Anastasakis, J.D. Joannopoulos, World Scientific, Singapore 1990, p. 29.

[15] D.O. Caldwell, J. Phys. G, Nucl. Part. Phys. 17, 5325 (1991).

[16] Kohei Itoh, W.L. IIansen, E.E. HIaller, J.W. Farmer, V.I. Ozhogin, A. Rudnev, A. Thikomirov, J. Mater. Sci., in press. 
[17] G. Davies, E.C. Lightowlers, V. Ozhogin, K. Itoh, W.L. Hansen, E.E. Haller, in: Proc. 5th Internat. Conf. on Shallow Impurities in Semiconductors: Physics and Control of Impurities, Ed. T. Taguchi, Mater. Sci. Forum 117\&118, 111 (1993).

[18] G. Davies, E.C. Lightowlers, K. Itoh, W.L. Hansen, E.E. Ialler, V. Ozhogin, Semicond. Sci. Technol. 7, 1271 (1992).

[19] H.D. Fuchs, C.H. Grein, C. Thomson, M. Cardona, W.L. Hansen, K. Itoh, E.E. Haller, Phys. Rev. B 43, 4835 (1991).

[20] G. Davies, J. Hartung, V. Ozhogin, K. Itoh, W.L. Hansen, E.E. Haller, Semicond. Sci. Technol. 8, 127 (1993).

[21] H.D. Fuchs, P. Etchegoin, M. Cardona, K. Itoh, E.E. Haller, Phys. Rev. Lett. 70, 1715 (1993).

[22] K. Itoh, J. Wolk, E.E. Haller, A. Ramdas, to be published.

[23] V. Ozhogin, unpublished.

[24] T.Y. Tan, H.M. You, S. Yu, U. Gösele, W. Jäger, D.W. Boeringer, F. Zypman, R. Tsu, S.-T. Lee, J. Appl. Phys. 72, 5208 (1992).

[25] E.E. Haller, Semicond. Sci. Technol. 5, 319 (1990).

[26] E.E. Haller, N.P. Palaio, M. Rodder, W.L. IIansen, E. Kreysa, in: Proc. 4th Internat. Conf. on Neutron Transmutalion Doping of Semiconductor Materials, Nat. Bureau of Standards, June 1-2, 1982, Ed. R.D. Larrabee, Plenum Press, 1984, p. 21.

[27] R.N. Hall, Inst. Phys. Conf. Scr. 23, 190 (1975); see also IEEE Trans. Nucl. Sci. NS-21, No. 1, 260 (1974).

[28] T.M. Lifshits, F.Ya. Nad,.Sov. Phys. Dokl. 10, 532 (1965); see also Sh.M. Kogan, T.M. Lifshits, Phys. Status Solidi A 39, 11 (1977).

[29] E.E. Haller, Phys. Rev. Lett. 40, No. 9, 584 (1978).

[30] J.M. Kahn, R.E. McMurray, Jr., E.E. Haller, L.M. Falicov, Phys. Rev. B 36, No. 15, 8001 (1987).

[31] P.J.H. Dentener, C.G. Van de Walle, S.T. Pantelides, Phys. Rev. Lett. 62, 1884 (1989).

[32] J.M. Kahn, L.M. Falicov, E.E. Haller, Phys. Rev. Lett. 57, 2077 (1986).

[33] H. Navarro, J. Griffin, E.E. Ilaller, J. Phys. C, Solid State Phys. 21, 1511 (1987).

[34] H. Navarro, E.E. Haller, F. Keilmann, Phys. Rev. B 37, 10822 (1988).

[35] B.L. Gel'mont, V.G. Golubev, V.I. Ivanov-Omskii, G.I. Kropotov, E.E. Haller, in: Proc. 19th Internat. Conf. on the Physics of Semiconductors, Ed. W. Zawadzki, Institute of Physics, Polish Academy of Sciences, Wrocław 1988, p. 1281.

[36] E.E. Haller, Chapter 11 in IIydrogen in Semiconductors, in series Semiconductors and Semimetals, Vol. 34, Eds. J. Pankove, N. Johnson, Academic Press, Orlando 1991, p. 351.

[37] K. Muro, A.J. Sievers, Phys. Rev. Lelt. 57, 897 (1986).

[38] K. Muro, A.J. Sievers, in: Proc. 18lh Internat. Conf. Physics of Semiconductors, Ed. O. Engström, World Scientific, Singapore 1987, p. 891.

[39] R.E. Peale, K. Muro, A.J. Sievers, Phys. Rev. B 41, 5881 (1990).

[40] E. Artacho, L.M. Falicov, Phys. Rev. B 43, 12507 (1991).

[41] J.M. Kahn, L.M. Falicov, E.E. Haller, Phys. Rev. Lett. 57, 2077 (1986).

[42] M.S. Schnoller, IEEE Trans. Electron Devices ED-23, 797 (1976). 
[43] See articles in Proc. 4lh Internat. Conf. on Neutron Transmutation Doping of Semiconductor Materials, Nat. Bureau of Standards, Ed. R.D. Larabee, Plenum Press, 1984.

[44] E.E. Haller, submitted to J. Infrared Phys.

[45] B.I. Shklovskii, A.L. Efros, Electronic Properties of Doped Semiconductors, Springer series in Solid State Sciences, Vol. 45, Springer-Verlag, Berlin 1984.

[46] M.I. Alonso, M. Cardona, G. Kanellis, Sol. State Commun. 60, 479 (1989); Corrigendum in Solid State Commun. 70, 1 (1989).

[47] S. Zollner, M. Cardona, S. Gopalan, Phys. Rev. B 45, 3376 (1992).

[48] W.L. Hansen, F.S. Goulding, E.E. Haller, IEEE Trans, Nucl. Sci. NS-26, No. 1, 276 (1979).

[49] I. Silier, S. Subramanian, E. Diessel, H.-J. Queisser, E. Bauser, Appl. Phys. Lett., in press.

[50] Table of Isotopes, Eds. C.M. Lederer, V.S. Shirley, 7th ed. Wiley, New York 1978. 